\title{
Ligature of the Left Main Coronary Artery after Surgery in Kawasaki Disease: Case Report
}

\author{
Laura Varela Barca' ${ }^{1}$, MD; José López-Menéndez ${ }^{1}$, MD; Ana Redondo Palacios ${ }^{1}$, MD; Jorge Rodríguez-Roda Stuart ${ }^{1}$, MD
}

DOI: $10.21470 / 1678-9741-2018-0029$

\begin{abstract}
We report a case of a 23-year-old man who was diagnosed with Kawasaki disease that progressed to a coronary aneurysm in the left main coronary artery (LMA). He had suffered from acute coronary syndrome and then underwent an emergent percutaneous coronary angioplasty, in which a polyurethanecovered stent was placed inside the aneurysm. The stent was thrombosed one year later, despite the patient had been treated with anticoagulant and antiplatelet therapy. Emergency percutaneous intervention was then performed. LMA was
\end{abstract}

reopened and stent malposition was observed. Therefore, urgent coronary bypass grafting was performed in which a high degree of competitive flow was observed through the reopened stent. LMA was ligated at the inflow of the aneurysm, resulting in an improvement of graft flow. Left main ligature has not been previously reported.

Keywords: Mucocutaneous Lymph Node Syndrome. Acute Coronary Syndrome. Coronary Aneurysm. Coronary Artery Bypass, Off-Pump.

\section{Abbreviations, acronyms \& symbols}

\section{ACS = Acute coronary syndrome}

CABG = Coronary artery bypass grafting

IMA = Internal mammary arteries

LAD = Left anterior descending coronary artery

LCX $\quad=$ Left circumflex artery

LMA = Left main coronary artery

$\mathrm{PI} \quad=$ Pulsatility index

RCA = Right coronary artery

\section{INTRODUCTION}

Kawasaki disease is a type of vasculitis that affects small and medium-sized arteries with predilection for coronary arteries. It is more prevalent in Asian countries, and the most significant complication is the development of coronary artery aneurysms that occur between $15-25 \%$ of the cases.

Approximately, 50\% of coronary artery aneurysms regress, but other moderately sized aneurysms can lead to clinical problems even years after an acute episode of Kawasaki disease ${ }^{[1]}$. Although the death rate associated with Kawasaki disease is

${ }^{1}$ Cardiac Surgery Department, Hospital Ramón y Cajal, Madrid, Spain.

This study was carried out at Cardiac Surgery Department, Hospital Ramón y Cajal, Madrid, Spain. very low $(<0.1 \%)$, myocardial infarction due to stenotic lesions or thrombosis of aneurysms continues to be a serious problem, despite diagnostic and therapeutic advances ${ }^{[2]}$.

Percutaneous coronary angioplasty is indicated in localized stenotic lesions not involving the coronary ostia, but coronary artery bypass grafting (CABG) should be recommended in cases with myocardial ischemia caused by multivessel disease ${ }^{[3]}$.

We report a case of urgent CABG in a patient diagnosed with Kawasaki disease, despite adequate flow through a stent in the left main coronary artery (LMA). Competitive flow through coronary grafts significantly decreases the grafts' durability and could facilitate graft thrombosis ${ }^{[4]}$. There are previously published reports about the ligature of the right coronary artery (RCA) after $\mathrm{CABG}^{[5]}$, but to our knowledge the ligature of LMA has not been previously reported.

\section{CASE REPORT}

This case report was prepared following the CARE Guidelines ${ }^{[6]}$ and the patient provided informed consent for its publication.

We present a case of a 23-year-old man who was diagnosed with Kawasaki disease at the age of 13 months when he suffered an acute coronary syndrome (ACS). Coronary artery aneurysms

\footnotetext{
Correspondence Address:

Laura Varela Barca

(iD) http://orcid.org/0000-0002-4605-8801

Ctra. Colmenar Viejo km 9,100 - Madrid, Spain

Zip code: 28034

E-mail: lauravarela21089@gmail.com
} 
in RCA and LMA were observed, as well as partial thrombosis in both. Accordingly, he was treated with fibrinolysis and anticoagulant therapy. Complete regression of the RCA aneurism was observed six years after the diagnosis of Kawasaki disease, however the LMA aneurysm persisted with involvement of the anterior descending artery ostium.

One year before the current episode, the patient suffered from ACS due to a severe calcified lesion of the LMA aneurysm (Figure 1). He underwent an emergency percutaneous coronary angioplasty, and a polyurethane-covered stent (PK Papyrus, Biotronik ${ }^{\circledR}$, Berlin, Germany) was inserted. The patient remained asymptomatic for one year.

In the current episode, he was readmitted to the emergency department in cardiogenic shock in which noradrenalin employment was necessary to achieve hemodynamic stabilization. He suffered from ACS caused by a complete occlusion of the stent despite anticoagulation and dual antiplatelet therapy. It was possible to percutaneously reopen the occluded LMA and adequately restore coronary flow. However, there was evident severe stent malposition in the distal part of the LMA. Due to this concerning finding, the patient was accepted for emergency cardiac surgery. He underwent offpump CABG 24 hours after the episode, in which both internal mammary arteries (IMA) were dissected. The right IMA was grafted to the left medial anterior descending artery, and the left IMA was grafted to the first marginal artery. A transit-time flow meter was employed to assess graft patency (Medistim ${ }^{\circledR}$, Oslo, Norway). Although flow measures and pulsatility index (PI) were optimal $(60 \mathrm{ml} / \mathrm{min}$ in the right IMA graft and $50 \mathrm{ml} / \mathrm{min}$ in

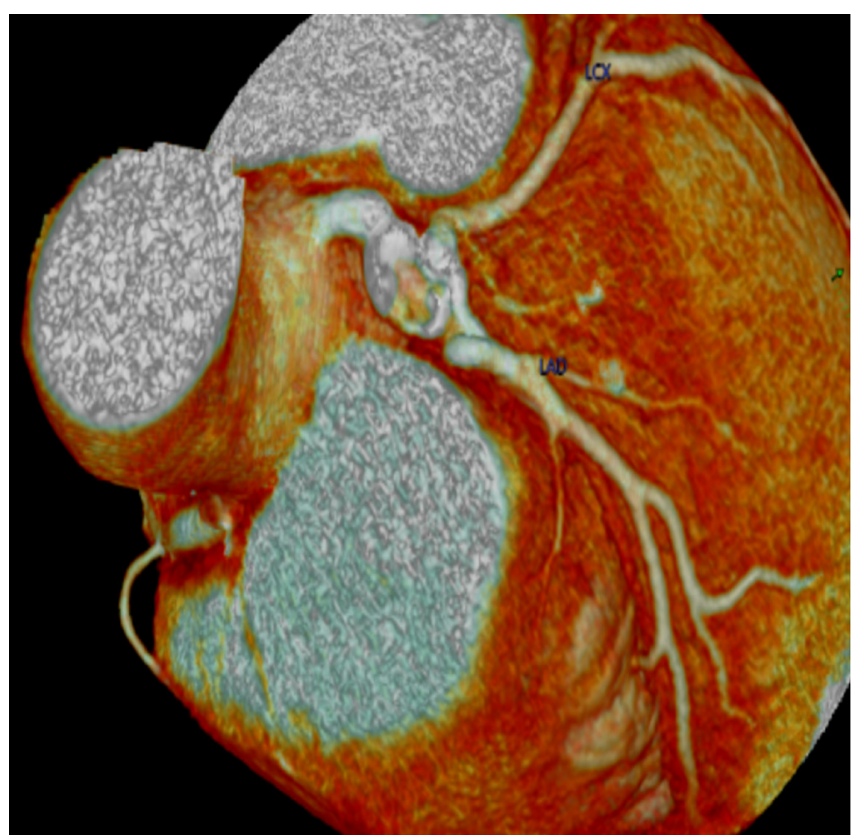

Fig. 1 - Coronary artery computed tomographic reconstruction showing an aneurysmatic lesion of the left main artery.

$L A D=$ left anterior descending coronary artery; $L C X=$ left circumflex artery

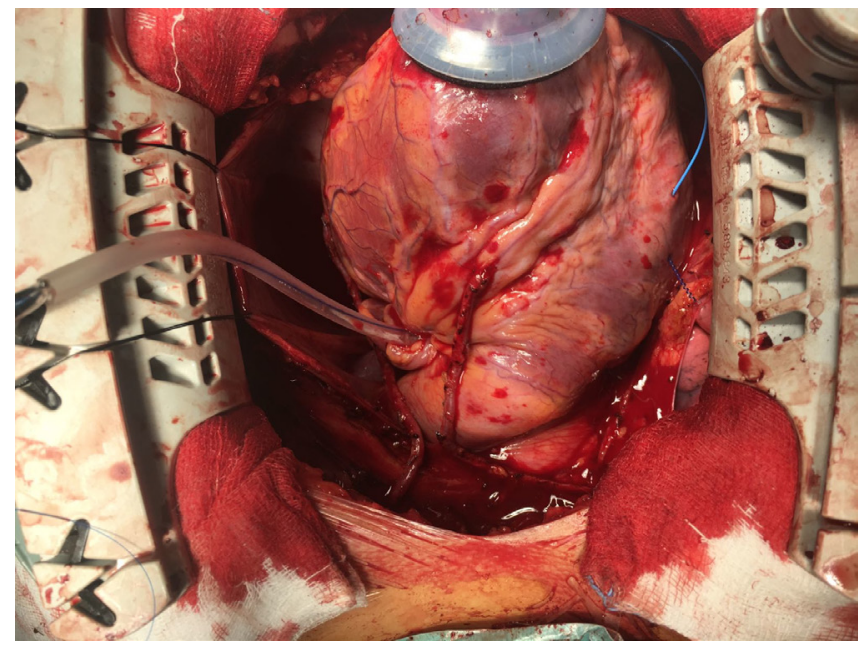

Fig. 2 - Image of the surgical field: testing with a transitory tourniquet on the left main artery, prior to permanent ligature.

the left IMA graph, with a PI of 2.4 and $75 \%$ insufficiency), a high degree of competitive flow was observed through the recently reopened LMA. A transitory tourniquet was applied to the LMA (Figure 2) and there was great improvement in the flow through the grafts with complete disappearance of any competitive flow $(150 \mathrm{ml} / \mathrm{min}$ and $80 \mathrm{ml} / \mathrm{min}$ in right and left IMA, respectively, and insufficiency decreased to 0\%). Therefore, the LMA was ligated at the inflow of the aneurysm.

The patient was discharged after 24 hours in intensive care after surgery and a total stay of six days. The patient has remained asymptomatic since the procedure with a post-operative followup at 16 months to date.

\section{DISCUSSION}

Surgical revascularization for coronary lesions secondary to Kawasaki disease is relatively uncommon. However, CABG should be recommended in cases of patients with multivessel disease.

According to the current guidelines ${ }^{[3]}$, complete arterial revascularization should be used in young patients with small comorbidities in order to achieve good long-term graft patency. Left IMA should be used to bypass the left anterior descending artery, and one second IMA should be indicated to graft the left circumflex or right coronary in order to improve the likelihood of survival and to decrease reintervention ${ }^{[3]}$.

Off-pump CABG has been previously described as treatment for coronary artery aneurysms ${ }^{[5,7]}$. Off-pump surgery is a safe and less invasive procedure because it minimizes the complications of cardiopulmonary bypass ${ }^{[8]}$.

Since three decades ago, IMA graft was first described rather than saphenous vein graft during $C A B G^{[9]}$; IMA are the preferred conduits for surgical revascularization. They have confirmed excellent long-term patency due to their endothelial function ${ }^{[10]}$. IMA grafts have shown improved survival and reduced incidence of myocardial infarct, recurrent angina, and the need for repeated intervention ${ }^{[3,11]}$. 
In addition, considering that early thrombus formation in saphenous vein grafts has previously been reported, surgery using arterial grafts should be considered. Although in cases of non-severe stenosis in the native coronary arteries, the use of IMA is widely debated ${ }^{[4]}$. It is known that competitive blood flow reduces IMA graft patency. This reduction was described to be particularly evident in diastole ${ }^{[12]}$.

To avoid the risk of graft failure due to highly competitive flow we performed a transient ligature in LMA. There was great improvement of flow through the grafts, with complete disappearance of competitive flow. Therefore, the LMA was ligated at the inflow of the aneurysm. Since there is an absence of reports in literature about LMA ligation, we believe that this technique is a good option to avoid competitive flow through a patent calcified giant aneurysm after Kawasaki disease.

\section{Authors' roles \& responsibilities}

LVB Substantial contributions to the conception or design of the work; or the acquisition, analysis, or interpretation of data for the work; drafting the work or revising it critically for important intellectual content; final approval of the version to be published

JLM Acquisition of information and design; final approval of the version to be published

ARP Design and images; final approval of the version to be published

JRRS Review of the document; final approval of the version to be published

\section{REFERENCES}

1. Gordon JB, Daniels LB, Kahn AM, Jimenez-Fernandez S, Vejar M, Numano $F$, et al. The spectrum of cardiovascular lesions requiring intervention in adults after Kawasaki disease. JACC Cardiovasc Interv. 2016;9(7):687-96.

2. Wei YJ, Zhao XL, Liu BM, Niu H, Li Q. Cardiac complications in 38 cases of Kawasaki disease with coronary artery aneurysm diagnosed by echocardiography. Echocardiography. 2016;33(5):764-70.

3. Hillis LD, Smith PK, Anderson JL, Bittl JA, Bridges CR, Byrne JG, et al. 2011 ACCF/AHA Guideline for coronary artery bypass graft surgery: a report of the American College of Cardiology Foundation/American Heart Association Task Force on Practice Guidelines. Circulation. 2011;124(23):e652-735.

4. Sabik JF 3rd, Lytle BW, Blackstone EH, Khan M, Houghtaling PL, Cosgrove DM. Does competitive flow reduce internal thoracic artery graft patency? Ann Thorac Surg. 2003;76(5):1490-6.

5. Iwamura T, Kikuchi K, Tambara K, Koike H, Kamikawa Y, Kawasaki S, et al. Off-pump coronary artery bypass grafting for angina pectoris with coronary artery aneurysm due to Kawasaki disease: reporting of a case. Kyobu Geka. 2009;62(6):500-3.

6. Riley DS, Barber MS, Kienle GS, Aronson JK, von Schoen-AngererT,Tugwell $P$, et al. CARE guidelines for case reports: explanation and elaboration document. J Clin Epidemiol. 2017;89:218-35.

7. Fridman MD, Owada CY, Gregory RD, Birnbaum PL. Off-pump double coronary artery bypass in a 14-year-old with Kawasaki disease. Ann Thorac Surg. 2017;104(4):e307-9.

8. Fudulu D, Benedetto U, Pecchinenda GG, Chivasso P, Bruno VD, Rapetto $F$, et al. Current outcomes of off-pump versus on-pump coronary artery bypass grafting: evidence from randomized controlled trials. J Thorac Dis. 2016;8(Suppl 10):S758-71.

9. Loop FD, Lytle BW, Cosgrove DM, Stewart RW, Goormastic M, Williams GW, et al. Influence of the internal-mammary-artery graft on 10-year survival and other cardiac events. N Engl J Med. 1986;314(1):1-6.

10. Davierwala PM, Mohr FW. Bilateral internal mammary artery grafting: rationale and evidence. Int J Surg. 2015;16(Pt B):133-9.

11. Taggart DP. Current status of arterial grafts for coronary artery bypass grafting. Ann Cardiothorac Surg. 2013;2(4):427-30.

12. Glineur $D$, Hanet $C$. Competitive flow in coronary bypass surgery: is it a problem? Curr Opin Cardiol. 2012;27(6):620-8.

This is an open-access article distributed under the terms of the Creative Commons Attribution License. 